\title{
SINOPSE DO GÊNERO COCCOCYPSELUM P. BROWNE (RUBIACEAE) NO ESTADO DE SÃO PAULO, BRASIL
}

\author{
Cristina Bestetti Costa \\ Maria Candida Henrique Mamede
}

Biota Neotropica v2 (n1) - http://www.biotaneotropica.org.br/v2n1/pt/abstract?article+BN01402012002

Recebido 19 de fevereiro de 2002

Modificado em 03 de maio de 2002

Aceito em 21 de maio de 2002

\begin{abstract}
Cristina Bestetti Costa: Instituto de Botânica (http://www.ibot.sp.gov.br/), Caixa Postal 4005, 01061-970, São Paulo, SP. Bolsista da CAPES. Autor para correspondência: bestetti@usp.br, bestetti@ directnet.com.br

Maria Candida Henrique Mamede: Instituto de Botânica, Caixa Postal 4005, 01061-970, São Paulo, SP. Bolsista de Produtividade em Pesquisa do CNPq. E-mail: mcmamede@uol.com.br
\end{abstract}

\begin{abstract}
(Synopsis of the genus Coccocypselum P. Browne (Rubiaceae) in the State of São Paulo, Brazil). The genus Coccocypselum comprises about 35 Neotropical species, distributed from Mexico to Argentina. It is characterized by contracted inflorescences, distylous lilac flowers, bilocular multiovulate ovary, and usually carnose, blue or purplish berries, which sometimes mature into dry. Eight species were recognized in the state of São Paulo: C. campanuliflorum (Hook.) Cham. \& Schltdl., C. condalia Pers., C. cordifolium Nees \& Mart., C. erythrocephalum Cham. \& Schltdl., C. hasslerianum Chodat, C. krauseanum Standl., C. lanceolatum (Ruiz \& Pav.) Pers. and C. lymansmithii Standl. All the species are widespread in the Atlantic forest, except for $C$. lanceolatum, which grows either on "cerradão" vegetation and C. lymansmithii, which grows only on open fields in Serra da Mantiqueira. Illustrations, comments and observations on the morphology, taxonomy, geographic distribution and phenology are presented, and a key to the species is provided.
\end{abstract}

Key Words: floristic, Coccocypselum, Rubiaceae, São Paulo

\section{Resumo}

(Sinopse do gênero Coccocypselum P. Browne (Rubiaceae) no Estado de São Paulo, Brasil). Coccocypselum é um gênero herbáceo com cerca de 35 espécies distribuídas exclusivamente nos Neotrópicos, desde o México até a Argentina. Caracteriza-se pelas cimeiras contraídas, flores distílicas, lilases, ovário bilocular, multiovulado e, usualmente, frutos carnosos azuis ou vináceos, às vezes tornando-se secos. Foram reconhecidas oito espécies de Coccocypselum em São Paulo: C. campanuliflorum (Hook.) Cham. \& Schltdl., C. condalia Pers., C. cordifolium Nees \& Mart., C. erythrocephalum Cham. \& Schltdl., C. hasslerianum Chodat, C. krauseanum Standl., C. lanceolatum (Ruiz \& Pav.) Pers. e C. lymansmithii Standl. A maioria das espécies ocorre na floresta ombrófila densa do litoral do Estado, à exceção de $C$. lymansmithii, encontrada apenas nos campos montanos da Serra da Mantiqueira, e de C. lanceolatum, que se estende até o interior do Estado. São apresentados comentários sobre morfologia e taxonomia, ilustrações, e dados sobre distribuição geográfica e fenologia, alem de uma chave para as espécies estudadas.

Palavras-chave: florística, Coccocypselum, Rubiaceae, São Paulo 


\section{Introdução}

O gênero Coccocypselum compreende cerca de 35 espécies de ampla distribuição nos Neotrópicos. Apresenta distribuição disjunta do México até a Colômbia, e nas regiões Centro-Oeste, Sudeste e Sul do Brasil até a Argentina (Standley \& Williams 1975, Andersson 1992). No Brasil encontra-se a maior diversidade do gênero, com cerca de 21 espécies, notadamente na Mata Atlântica (Andersson 1992).

Schumann (1889) apresenta uma chave para as espécies brasileiras de Coccocypselum, baseada principalmente na forma e tamanho dos lobos do cálice e na morfologia das inflorescências de sete espécies, com referência de duas espécies apenas para o Estado de São Paulo, C. condalia Pers. e C. guianense (Aubl.) K. Schum. Loefgren (1896) reportou a ocorrência de quatro espécies (C. canescens Willd. ex Roem. \& Schult., C. condalia, $C$. erythrocephalum Cham. \& Schltdl. e C. guianense) no município de Santo André (Estação Campo Grande). $C$. condalia e $C$. canescens foram também referidas para o município de São Paulo (Usteri 1911), e, além destas, $C$. erythrocephalum, C. guianense e C. cordatum (Krause \& Hoehne 1922). Esta última foi sinonimizada posteriormente em C. hasslerianum Chodat por Smith \& Downs (1956).

Em levantamentos florísticos mais recentes, JungMendaçolli (1994, 1999) referiu C. campanuliflorum (Hook.) Cham. \& Schltdl., C. condalia, C. hasslerianum, C. lanceolatum e C. cf. nummulariifolium Cham. \& Schltdl. como nativas no Parque Estadual Fontes do Ipiranga (Município de São Paulo), e além das quatro primeiras, C. cordifolium Nees \& Mart. e C. krauseanum, no Parque Estadual da Ilha do Cardoso.

O presente trabalho teve como objetivos o levantamento e estudo taxonômico das espécies de Coccocypselum como contribuição ao conhecimento da composição e diversidade florística do Estado de São Paulo, além de rever e atualizar as identificações dos materiais depositados nos herbários paulistas.

\section{Material e métodos}

O Estado de São Paulo, com aproximadamente $250.000 \mathrm{~km}^{2}$, está situado entre os paralelos $20^{\circ}-26^{\circ} \mathrm{S}$ e $44^{\circ}-55^{\circ} \mathrm{W}$, sendo atravessado pelo Trópico de Capricórnio. Situa-se numa região de transição entre os climas quentes das latitudes baixas e os climas mesotérmicos, de tipo temperado, das latitudes médias, com regime de chuvas tipicamente de ritmo tropical (Nimer 1979). As principais formações existentes no Estado são constituídas pelos cerrados, pelas estepes (campos) e pelas florestas ombrófila densa, ombrófila mista e estacional semidecidual (Veloso et al. 1991).

Foram realizadas coletas em áreas do Estado que contemplassem todas as formações vegetais existentes no território paulista. Os procedimentos utilizados nas coletas foram os usuais para os estudos de taxonomia de
Fanerógamas (Mori et al. 1989). Todo o material coletado foi incorporado ao acervo do Herbário do Instituto de Botânica e duplicatas distribuídas aos principais herbários paulistas. A fim de complementar o levantamento das espécies ocorrentes no Estado de São Paulo e visando obter tanto material quanto possível de cada táxon para análise satisfatória da variabilidade morfológica, distribuição geográfica e fenologia, foi realizado levantamento do material botânico depositado em alguns herbários nacionais, através de visitas e solicitações de empréstimo. Foram examinadas todas as coleções disponíveis dos herbários BOTU, ESA, HB, HRCB, IAC, PMSP, R, RB, SP, SPF, SPFR e UEC (siglas e acrônimos segundo http://www.nybg.org/bsci/ih/), além do herbário da Universidade Federal de São Carlos (UFSCar).

A terminologia morfológica de hábito, indumento, forma das folhas, estruturas das inflorescências, flores e frutos, segue o proposto por Radford et al. (1974). A análise da distribuição geográfica dos táxons foi feita com base nos dados obtidos a partir das etiquetas de herbário, bem como através dos dados da literatura, principalmente Standley (1930a), Smith \& Downs (1956), Andersson (1992), Gomes (1996) e Dubs (1998). Os nomes populares citados foram obtidos das anotações contidas nas etiquetas das exsicatas analisadas. Os dados sobre épocas de floração/frutificação e coloração de flores e frutos foram obtidos através das observações de campo e das informações contidas nos rótulos.

\section{Resultados}

Coccocypselum P. Browne, Civ. nat. hist. Jamaica: 144, pl.6, f. 2.1756, nom. cons.

O gênero caracteriza-se principalmente pelo hábito herbáceo, estípulas unilaciniadas, inflorescências congestas, flores tetrâmeras, distílicas, ovário bilocular, multiovulado, placenta horizontal e bagas azuis ou roxas, com muitas sementes. É um gênero de fácil reconhecimento, com vários problemas de taxonomia ao nível específico que, quando solucionados, devem resultar na sinonimização de muitas espécies (Costa, em prep.). Está representado no Estado por oito espécies.

Chave para as espécies de Coccocypselum no Estado de São Paulo

1. Ervas glabras, glabrescentes ou seríceas, tricomas apressos, esparsamente distribuídos, ou concentrados na margem das folhas.

2. Folhas com lâminas ovais ou lanceoladas, $2-4,5 \mathrm{~cm}$ compr., 1-2,5 cm larg.; cimeiras pedunculadas, pedúnculo 10-30 mm compr., 7-8(-11) flores; lobos do cálice lanceolados, 2-6 mm compr., totalmente glabros ou ciliados; bagas obovóides ou elipsóides 2. C. condalia

2. Folhas com lâminas ovais, cordiformes ou orbiculares, 0,7-7 cm compr., 0,8-6,5 cm larg.; cimeiras sésseis ou com pedúnculos 2-17 mm compr., 
1-6 flores; lobos do cálice subulados ou linearlanceolados, 2-4,5 mm compr., seríceos em ambas as faces ou ciliados; bagas globosas ou depressoglobosas.

3. Folhas com lâminas ovais ou cordiformes, $2-7 \mathrm{~cm}$ compr., 2-6,5 cm larg.; cimeiras geralmente sésseis, raramente com pedúnculos $2-17 \mathrm{~mm}$ compr., 3-6 flores; lobos do cálice linearlanceolados, 3,5-4,5 $\mathrm{mm}$ compr., glabros, margem ciliada. 6. C. krauseanum

3. Folhas com lâminas cordiformes ou orbiculares, 0,7-1,2 cm compr., 0,8-1,2 cm larg.; cimeiras com pedúnculos 5-15 mm compr., unifloras, raramente bifloras; lobos do cálice subulados, 2-2,2 $\mathrm{mm}$ compr., seríceos em ambas as faces..

8. C. lymansmithii

1. Ervas velutinas ou hirsutas, tricomas eretos, densamente distribuídos por toda a planta.

4. Folhas com lâminas ovais ou lanceoladas; bagas elipsóides ou obovóides.

5. Lâminas 4,5-9,5 cm compr., 3-4,5 cm larg., base cordada, raramente atenuada, truncada ou levemente oblíqua, nervuras secundárias 6-10 pares; cimeiras sésseis ou com pedúnculos até 5 $\mathrm{mm}$ compr., 7-10 flores; lobos do cálice lineares ou lanceolados, hirsutos em ambas as faces ..5. C. hasslerianum

5. Lâminas 1,2-8,5 cm compr., 0,6-3,9 cm larg., base truncada, arredondada ou levemente oblíqua, nervuras secundárias 6-12 pares; cimeiras com pedúnculos com mais de $1 \mathrm{~cm}$ compr., 7-20 flores; lobos do cálice lineares, ovais ou lanceolados, velutinos em ambas as faces ou hirsutos apenas na face adaxial.

6. Ervas velutinas; lâminas 2,9-8,5 cm compr., 1$3,5 \mathrm{~cm}$ larg., nervuras secundárias 7-12 pares; cimeiras globosas, 10-20 flores; lobos do cálice ovais ou lineares, geralmente reflexos, velutinos em ambas as faces.

.7. C. lanceolatum

6. Ervas hirsutas; lâminas 1,2-6,8 cm compr., 0,63,9 cm larg., nervuras secundárias 6-8 pares; cimeiras semi-globosas, 7-10 flores; lobos do cálice lineares ou lanceolados, eretos, hirsutos apenas na face adaxial.

7. Lobos do cálice lineares.

4. C. erythrocephalum

7. Lobos do cálice lanceolados 2. C. condalia

4. Folhas com lâminas ovais, orbiculares, cordiformes ou reniformes; bagas globosas ou depresso-globosas.

8. Lâminas 1,4-3,4 cm compr., 1,6-3,1 cm larg., cordiformes ou reniformes, base cordada, nervuras secundárias 4 pares; cimeiras 6-7 flores; lobos do cálice lineares, face adaxial glabra, abaxial hirsuta; bagas livres entre si na base, pubescentes 3. C. cordifolium

8. Lâminas 1-2,7 cm compr., 1-2,1 cm larg., orbiculares, ovais ou cordiformes, raro reniformes, base arredondada, obtusa ou truncada, mais raramente cordada, nervuras secundárias 5-6(-7) pares; cimeiras 8-10 flores; lobos do cálice linear-espatulados ou lanceolados, ambas as faces hirsutas; bagas com base angulosa, unidas e glabras nesta região, hirsutas no ápice.....

1. C. campanuliflorum

1. Coccocypselum campanuli florum (Hook.) Cham. \& Schltdl., Linnaea 4: 140. 189. Hedyotis campanuliflora Hook., Bot. Mag. 55: tab. 2840. 1828.

Figuras - 1A-I

Nomes populares - hortelãnzinha (SP), jalapa, erva-derato $(\mathrm{RJ})$.

Material selecionado BRASIL: SÃO PAULO: Bertioga, 23S 51', 46W 8', 11/1989, M.A. Assis et al. 22426, fl., fr. (ESA, UEC); Boracéia, 22S 11', 48W 46', 27/11/1989, W. Spironello et al. 22287, fl. (ESA, SP, UEC); Cananéia, $25 \mathrm{~S}$ 0', 47W 55', 8/9/1994, C.A. Monteiro et al. 22, fl. (ESA, SP); Cotia, 23S 36', 46W 55', 4/1941, L. Constantino 120, fl. (RB); Iguape, 24S 42', 47W 33', 27/9/1996, R.J. Oliveira \& L.F.P. Gusmão s.n., fl. (SP 310949), 12/12/1992, E.A. Anunciação et al. 166, fl. (SP); Moji das Cruzes, 23S 31', 46W 11', 15/2/1997, C.Y. Kiyama 120, fl., fr. (SP); Peruíbe, 24S 19', 46W 59', 13/10/1995, C.B. Costa et al. 62, fl. (SP); São Paulo, 23S 32', 46W 38', 19/12/1996, R.J.F. Garcia et al. 961, fl. (PMSP, SP, UEC); Sete Barras, 24S 23', 47W 55', 16/2/1995, J.P. Souza et al. 136, fl., fr. (SP, UEC).

Distribuição geográfica e ecologia - Sul da Bahia até Santa Catarina, nas florestas ombrófilas densas, em bordas de matas e nos solos arenosos das restingas.

Caracteriza-se vegetativamente por possuir ramos vináceos, hirsutos, revestidos de tricomas multicelulares, eretos, finos, alvos ou vináceos, raro ferrugíneos. Apresenta ainda, lâmina foliar oval, orbicular ou cordiforme, mais raramente reniforme, e pecíolos curtos. As nervuras são proeminentes na face abaxial e mais tênues e esbranquiçadas na face adaxial. As suas características reprodutivas incluem inflorescências com pedúnculo longo, lobos do cálice lanceolados ou linear-espatulados, lobos e fauce da corola vináceos, tubo amarelado e frutos depresso-globosos, unidos na região basal. Os frutos de $C$. campanuliflorum distinguem-se dos das demais espécies do gênero, o que gerou muitas dúvidas com relação a sua verdadeira identidade. No início de seu desenvolvimento, são carnosos, alvos ou esverdeados. A impressão que se tem, ao analisar as populações no campo, é a de que tais frutos não completam seu desenvolvimento, permanecendo unidos pelas bases angulosas. A análise de alguns espécimes em herbário mostrou que os frutos possuem uma espécie de opérculo apical que se destaca à medida que o fruto seca. Estudos anatômicos realizados mostraram que os frutos de C. campanuliflorum são indeiscentes e apresentam estrutura semelhante aos das demais espécies de Coccocypselum (Costa \& Luchi, inéd.). Alguns materiais apresentaram ramos ferrugíneos, com folhas maiores, ovais e um número maior de pares de nervuras secundárias (7). Assemelha-se a $C$. cordifolium, 
diferindo por esta última apresentar lâmina foliar maior e cordiforme, pecíolos mais longos, lobos do cálice lineares, indumento hirsuto e bagas globosas e carnosas.

2. Coccocypselum condalia Pers., Syn. pl. 1: 132. 1805. Condalia repens Ruiz \& Pav., Fl. peruv. 1: 54, t. 84, fig. a, 1798.

Figuras - 1J-P, 4E, 5A-B

Material selecionado BRASIL: SÃO PAULO: Areias, 22S 34', 44W 41', 4/5/1997, A. Rapini 275, fr. (SP); Bom Sucesso de Itararé, 24S 19', 49W 8', 13/11/1994, V.C. Souza et al. 7168, fl. (ESA, SP, UEC); Campos do Jordão, 22S 44', 45W 35', 20/12/1995, S.A. Nicolau \& J.R. Manna de Deus 999, fl. (SP); 28/3/1994, I. Cordeiro et al. 1291, fr. (SP, UEC); Cananéia, 25S 0', 47W 55', 9/1994, M.E. Basso et al. 4, fr. (ESA, SP); Cunha, 23S 4', 44W 57', 20/3/1996, C.B. Costa et al. 207, fl., fr. (SP), 209, fl., fr. (SP, UEC); Diadema, 23S 41', 46W 37', 3/1996, R.J.F. Garcia et al. 788, fl., fr. (PMSP, SP, SPF, UEC); Embu-Guaçu, 23S 49', 46W 48', 26/10/1995, R. Simão-Bianchini et al. 823, fl. (SP); Iguape, 24S 42', 47W 33', 20/2/1996, C.B. Costa et al. 133, fl. (SP); Pindamonhangaba, 22S 55', 45W 27', 29/3/1994, L. Rossi et al. 1428, fr. (ESA, HRCB, SP, SPF, UEC); Piquete, 22S 36', 45W 10', 25/5/1996, L. Macias et al. 96126, fr. (SP, UEC); Salesópolis, 23S 31', 45W 50', 16/11/1994, R. Simão-Bianchini 603, fl. (SP); SantosPraia Grande, 23S 57', 46W 20', 11/1889, A. Loefgren in C.G.G. 4140, fl. (SP); Ubatuba, 23S 26', 45W 4', 10/1979, W. Mantovani 176, fl. (SP).

Distribuição geográfica e ecologia - Venezuela, Colômbia, Equador, Peru, Brasil, Paraguai e Argentina. No Brasil, ocorre nos estados do Mato Grosso, Mato Grosso do Sul e do sudeste ao sul do país, na floresta ombrófila densa, nas bordas de mata, campos, capoeiras, florestas da encosta e da crista da Serra do Mar, campos de altitude, em locais úmidos e, normalmente, sombreados.

Coccocypselum condalia caracteriza-se por possuir folhas ovais ou lanceoladas, glabras ou com tricomas apressos em ambas as faces ou, muitas vezes, abundantes apenas nas margens. Possui inflorescências pedunculadas com poucas flores, os lobos do cálice são lanceolados, glabros ou ciliados, mais raramente hirsutos na face abaxial. As bagas são elipsóides ou obovóides e azuis. Schumann (1889) mencionou a variação existente no indumento das folhas e flores, enfatizando ser o indumento na margem da folha, o mais freqüente. Nos diversos materiais analisados foi possível observar uma grande variação desse caráter, tendo sido encontrados espécimes completamente glabros até pubescentes, embora a maioria apresentasse tricomas no pecíolo, na margem e nas nervuras da face abaxial das folhas. $\mathrm{O}$ cálice apresenta lobos glabros ou ciliados e a corola é normalmente glabra na face abaxial. Alguns materiais, principalmente aqueles espécimes coletados no município de Cananéia, apresentam indumento hirsuto e lobos do cálice com tricomas na margem e na face abaxial.

3. Coccocypselum cordifolium Nees \& Mart., Nova Acta
Phys.-Med. Acad. Caes. Leop.-Carol. Nat. Cur. 12: 14. 1824.

Figuras - 1Q-S, 5C-D

Material selecionado BRASIL: SÃO PAULO: Boracéia, 22S 11', 48W 46', 11/1989, W. Spironello et al. 22276, fl. (UEC); Cananéia, 25S 0', 47W 55', 9/1996, M. Sugiyama s.n., fr. (SP 310946), s.d., M. Sugiyama 1411, fr. (SP); Cubatão, 23S 53', 46W 25', 27/5/1996, S. Martins s.n., fr. (SP 310948); Eldorado, 24S 31', 48W 6', 14/5/1994, R. Mello-Silva et al. 1001, fl. (SP, SPF); Iguape, 24S 42', 47W 33', 22/2/1996, C.B. Costa et al. 154, fr. (SP); Itararé, 24S 6', 49W 19', 25/1/1996, V.C. Souza et al. 10475, fl., fr. (ESA, SP); Pariquera-Açu, 24S 42', 47W 52', 30/9/1995, N.M. Ivanauskas 451, fr. (ESA, SP); Peruíbe, 24S 19', 46W 59', 28/10/1995, C.B. Costa et al. 106, est. (SP); Rio Claro, 22S 24', 47W 33', 1/1984, M.R. Pereira-Noronha 271, fl., fr. (HRCB); Santo André, 23S 39', 46W 32', G. Edwall in C.G.G. 1888, fl. (SP); São Paulo, 23S 32', 46W 38', 5/1945, W. Hoehne s.n., fr. (SP 193038), 3/5/1996, C.B. Costa et al. 219, fr. (SP), 4/4/1996, C.B. Costa et al. 216, fr. (SP); Sete Barras, 24S 23', 47W 55', 2/1995, J.P. Souza et al. 136, fr. (UEC); Ubatuba, 23S 26', 45W 4', 1/2/1996, H.F. Leitão Filho et al. 34591, fl. (ESA, SP, SPF, UEC).

Distribuição geográfica e ecologia - ocorre no México e América Central e no Brasil, no Distrito Federal e nas diversas formações da mata atlântica da Bahia até o sul do país. Comumente encontrada no estrato herbáceo das florestas ombrófilas densas, em locais úmidos e sombreados.

Caracteriza-se por possuir ramos hirsutos, folhas cordiformes ou reniformes, com pecíolos longos, tricomas retos, finos e macios por toda a planta, inflorescências pedunculadas e lobos do cálice lineares desiguais, com tricomas apenas na face abaxial, e frutos arredondados, azuis ou roxos.

Jung-Mendaçolli (1994) referiu C. cf. nummulariifolium no Parque Estadual das Fontes do Ipiranga (Mun. de São Paulo), baseando-se no material W. Hoehne s.n. (SP 193038). Apesar de apresentar folhas menores e reniformes, com menor número de nervuras secundárias, a análise deste material e de novas coletas no Estado, acrescidas de observações de populações existentes no Parque, revelaram tratar-se na realidade de $C$. cordifolium. C. reitzii L.B. Sm. \& Downs, com ampla distribuição no sul do Brasil, é uma espécie relacionada a C. cordifolium, diferenciando-se desta pelas inflorescências bifloras, lobos do cálice ciliados e pelo indumento com tricomas menores e mais esparsos (Smith \& Downs 1956).

4. Coccocypselum erythrocephalum Cham. \& Schltdl., Linnaea 4: 140. 1829.

Figuras - 2A-C

Material examinado BRASIL: SÃO PAULO: Cunha, 23S 4', 44W 57', 20/3/1996, C.B. Costa et al. 212, fl. (SP), 210, fr. (SP, UEC).

Distribuição geográfica e ecologia - Goiás, Bahia, Minas Gerais, Rio de Janeiro e São Paulo. Em São Paulo foi 
coletada na borda de floresta ombrófila densa no norte do Estado.

Esta espécie caracteriza-se pelos ramos e folhas hirsutas, folhas ovais com base arredondada, 6-7 pares de nervuras secundárias e inflorescências pedunculadas com 7-10 flores. Muito semelhante a $C$. hasslerianum, diferencia-se desta pelas folhas com base arredondada e inflorescências pedunculadas. Foi descrita por Chamisso \& Schlechtendal (1829) e referida sua ocorrência nos Estados da Bahia, Minas Gerais, Rio de Janeiro e Santa Catarina por Schumann (1889).

C. erythrocephalum foi referida para São Paulo por Krause \& Hoehne (1922), com base no material F.C. Hoehne s.n. (SP 779), o qual se assemelhava a outros materiais coletados em Minas Gerais, porém, com folhas mais curtas e mais largas. A análise deste material mostrou tratar-se na verdade de $C$. lanceolatum. $\mathrm{Na}$ lista das espécies catalogadas pela "Commissão Geográphica e Geológica da Província de São Paulo”, Loefgren (1896) mencionou $C$. erythrocephalum, citando uma coleta da Estação Campo Grande (Mun. de Santo André) (C.G.G. 1888), que após análise cuidadosa foi identificado neste trabalho como $C$. cordifolium. Portanto, podemos afirmar que esta é a primeira referência da espécie para o Estado.

Assemelha-se a $C$. gardneri Standl., descrita para Minas Gerais e caracterizada pelos ramos pilosos ou glabrescentes, lâminas lanceolado-oblongas ou raramente ovais com base obtusa, seis pares de nervuras secundárias, pedúnculo da inflorescência com $1,5 \mathrm{~cm}$ e lobos do cálice hirsuto-ciliados (Standley 1936).

5. Coccocypselum hasslerianum Chodat, Bull. Herb. Boissier., sér. 2, 4: 169. 1904.

Figuras - 2D-M, 4B-C

Nome popular - espuma-de-sapo (SP).

Material selecionado BRASIL: SãO PAULO: Areias, 22S 34', 44W 41', 4/5/1997, A. Rapini 273, fr. (SP); Biritiba-Mirim, 23S 43', 46W 2', 10/5/1983, A. Custódio Filho 1353, fr. (SP); Cananéia, 25S 0', 47W 55', 8/1982, S.L. Jung-Mendaçolli \& A.C. Maruffa 502, fr. (SP), 500, fl., fr. (SP); Caraguatatuba, 23S 37', 45W 24', 5/1966, J.R. Mattos 13778 (IAC); Eldorado, 24S 31', 48W 6', 18/5/1994, I. Cordeiro \& M.A.B. Barros 1413, fl., fr. (SP, UEC); Ibiúna, 23S 39', 47W 13', 21/7/1995, J.B. Baitello \& J.A. Pastore 770, fr. (SP); Iguape, 24S 42', 47W 33', 19/6/1981, M.B. Vasconcellos et al. 12586, fr. (UEC); Ilhabela, 23S 46', 45W 21', 5/1970, D. Sucre 6974, fr. (RB); Iporanga, 24S 35', 48W 35', 20/5/1996, C.B. Costa et al. $225 \& 228$, fl., fr. (SP, SPF, UEC), 234, fr. (SP, UEC); Manduri, 23S 0', 49W 19', 7/1991, S. Romaniuc Neto et al. 1232, fr. (SP); Peruíbe, 24S 19', 46W 59', 9/1982, R. Rodrigues et al. 15665, fr. (UEC); Pindamonhangaba, $22 \mathrm{~S}$ 55', 45W 27', 2/1996, S. Nicolau 980, fl. (SP); Santa Isabel, 23S 18', 46W 13', 9/1936, M. Kuhlmann s.n. (SP 36285); Santo André, 23S 39', 46W 32', 11/1992, A. Custódio Filho \& M. Carra 1067, fr. (SP); São Paulo, 23S 32', 46W 38', 9/1994, S.A.P. Godoy et al. 232, fl., fr. (PMSP, SP); Ubatuba, 23S 26', 45W 4', 11/1990, A. Furlan et al. 1282, fl.
(HRCB, SP).

Distribuição geográfica e ecologia - ocorre no nordeste, centro-oeste, sudeste e sul do Brasil até o Paraguai e a Argentina. Habita borda de floresta ombrófila densa, em locais úmidos e sombreados.

C. hasslerianum caracteriza-se por possuir folhas normalmente oval-lanceoladas, com base cordada e pecíolos longos. É uma erva hirsuta, cujos tricomas longos e eretos deixam cicatrizes na superfície das folhas. Além disso, possui inflorescências normalmente sésseis ou com pedúnculo muito curto (até $5 \mathrm{~mm}$ ), lobos do cálice lineares, hirsutos apenas na face abaxial ou, mais raramente, também no ápice da face adaxial. A presença de inflorescências sésseis ou pedunculadas sempre foi considerada pelos autores que estudaram o gênero como um caráter importante na distinção das espécies. $C$. hasslerianum apresenta inflorescências sésseis na maioria dos materiais examinados, sendo um caráter realmente importante na sua identificação. São poucas as espécies do gênero que possuem inflorescências sésseis ou subsésseis. C. aureum (Spreng.) Cham. \& Schltdl. possui inflorescência séssil, porém apresenta ramos subferrugíneos, vilosos, folhas oval-lanceoladas ou lanceoladas, com base aguda ou arredondada, e bagas globosas (Schumann 1889).

Outras espécies que se assemelham a $C$. hasslerianum são C. hirsutum Bartl. ex DC., C. hispidum (Standl.) Standl. e C. brevipetiolatum Steyerm. Esta última ocorre no norte da América do Sul e região dos Andes (Andersson 1992). C. hispidum é uma erva hirsuta com inflorescências sésseis, com distribuição restrita à América Central (Standley 1930b), enquanto $C$. hirsutum é uma erva hirsuta, com folhas largamente ovais, de ápice agudo e base obtusa, pecíolos curtos, inflorescências pedunculadas e poucas flores. Segundo Andersson (1992), C. hirsutum apresenta ampla distribuição, sendo referida inclusive para a região sudeste, diferenciando-se de $C$. hasslerianum apenas pela presença de inflorescências pedunculadas. Apesar de ser possível observar variação de tamanho do pedúnculo para algumas espécies de Coccocypselum, em $C$. hasslerianum esta característica permaneceu constante, tendo sido adotada como característica diagnóstica. Uma análise mais ampla, incluindo materiais de espécies próximas, poderá auxiliar no entendimento destas variações e sugerir muitas sinonimizações.

6. Coccocypselum krauseanum Standl., Field Mus. Nat. Hist., Bot. Ser. 8(3): 164. 1930.

Figuras - 2N-R, 5E-F

Material selecionado BRASIL: SÃO PAULO: BiritibaMirim, 23S 34', 46W 2', 15/3/1985, I.C.C. Macedo \& A. Custódio Filho 55, fr. (SP); Cananéia, 25S 0', 47W 55', 7/1989, F. Barros s.n., fr. (SP 238603); Caraguatatuba, 23S 37', 45W 24', 25/5/1996, J.R. Mattos 13768, fr. (SP); Cunha, 23S 4', 44W 57', 21/3/1996, C.B. Costa et al. 211, fr. (SP, UEC); Eldorado, 24S 31', 48W 6', 3/9/1995, V.C. Souza et al. 9029, fl., fr. (ESA, HRCB, SP, SPF, UEC); Ilhabela, 23S 46', 45W 21', 6/1991, V.C. Souza \& A.F. 
Fierro 2555, fr. (ESA); Iporanga, 24S 35', 48W 35', 25/5/1996, C.B. Costa et al. 229, 23/5/1996, C.B. Costa et al. 242, 22/5/1996, C.B. Costa et al. 246 fr. (SP), 21/5/1996, C.B. Costa et al. 239, fr. (SP, SPF, UEC); Miracatu, 24S 16', 47W 27', 19/4/1994, J.R. Pirani \& R.F. Garcia 3084, fr. (SP, SPF); Moji das Cruzes, 23S 31', 46W 11', 28/5/1980, C.F.S. Muniz et al. 151, fr. (SP); Nazaré Paulista, 23S 10', 46W 23', 6/1996, V.C. Souza et al. 11229, fr. (ESA); PariqueraAçu, 24S 42', 47W 52', 19/4/1995, N.M. Ivanauskas 134, fr. (ESA, SP); Pindamonhangaba, 22S 55', 45W 27', 1/1997, S. Nicolau 1003, fl. (SP); Ribeirão Grande, 24S 5', 48W 21', 8/5/1997, M.G.L. Wanderley et al. 2245, fr. (SP); Santo André, 23S 39', 46W 32', 31/1/1996, M. Sugiyama et al. 1406, fl., fr. (SP); São José do Barreiro, 22S 38', 44W 34', 19/7/1994, E.L.M. Catharino \& L. Rossi 1967, fr. (SP); São Miguel Arcanjo, 23S 52', 47W 59', 1/1995, P.L.R. Moraes \& N.M. Ivanauskas 1107, fl. (ESA, IAC); São Paulo, $23 \mathrm{~S}$ 32', 46W 38', 3/5/1996, C.B. Costa et al. 217, fr. (SP); Sorocaba, 23S 30', 47W 27', 18/7/1902, E. Hemmendorff 483, fr. (R); Tapiraí, 23S 57', 47W 30', 11/5/1994, R. MelloSilva et al. 907, fr. (HRCB, SP, SPF, UEC); Ubatuba, 23S 26', 45W 4', 31/1/1996, H.F. Leitão Filho et al. 34566, fl., fr. (SP, UEC).

Distribuição geográfica e ecologia - Sudeste e sul do Brasil, nas matas úmidas do litoral dos Estados do Espírito Santo até Santa Catarina. Em algumas regiões aparecem grandes populações, forrando o chão da mata; em outros locais, entretanto, é extremamente rara. Cresce sobre solos úmidos e sombreados das florestas ombrófilas densas, muitas vezes próximo a cursos d'água.

Coccocypselum krauseanum caracteriza-se por apresentar inflorescências geralmente sésseis, com poucas flores. Dentre as espécies brasileiras, apenas $C$. aureum e C. sessiliflorum Standl. compartilham este caráter (Standley 1930a, 1936). C. aureum diferencia-se de $C$. krauseanum por ser uma erva hirsuta, com folhas lanceoladas. A análise dos protólogos e dos materiais-tipo de $C$. krauseanum e de $C$. sessiliflorum, permitiu verificar que ambas diferenciam-se apenas pela dimensão das folhas. O estudo das populações no Estado de São Paulo demonstrou que há uma grande variação no tamanho dos entrenós, dos pecíolos e lâminas foliares, e das estruturas reprodutivas, em geral relacionada ao estágio de desenvolvimento. Uma abordagem mais ampla e minuciosa poderá demonstrar que $C$. sessiliflorum é, provavelmente, sinônimo de $C$. krauseanum.

Ao contrário das outras espécies de Coccocypselum que apresentam suas populações com flores e frutos simultaneamente, esta espécie apresenta, normalmente, épocas de floração e frutificação distintas. Os frutos são bastante característicos, normalmente em número de três por infrutescência, arredondados, roxos, vistosos, brilhantes e facilmente visualizados nas populações, mesmo quando encobertos pelas folhas, sendo esta uma condição freqüente.

7. Coccocypselum lanceolatum (Ruiz \& Pav.) Pers., Syn. pl. 1: 132. 1805. Condalia lanceolata Ruiz \& Pav., Fl.
Peruv. 1: 54.1798.

Figuras - 3A-O, 4D

Material selecionado BRASIL: SÃO PAULO: Amparo, 22S 42', 46W 45', 30/8/1943, M. Kuhlmann 1271, fr. (SP); Areias, 22S 34', 44W 41', 4/5/1997, A. Rapini 274 \& 276, fr. (SP); Bananal, 22S 41', 44W 19', 9/5/1995, S.L. Proença et al. 42, fl., fr. (SP, SPF, UEC); Bauru, 22S 18', 49W 3', 6/1996, V.C. Souza \& J.P. Souza 11290, fr. (ESA); Bocaina, 22S 8', 48W 31', 3/1952, E. Pereira s.n., fr. (RB 7421); Botucatu, 22S 53', 48W 26', 10/1973, J.O. Sartori 51, fr. (BOTU): Cajuru, 21S 16', 47W 18', 4/1990, A. Sciamarelli \& J.V.C. Nunes 642, fl. (SPF, SPFR, UEC); Cananéia, 25S 0', 47W 55', 5/1983, S.L. Jung-Mendaçolli 566, fr. (SP); Capão Bonito, 24S 0', 48W 20', 12/1991, R. Romero et al. 421, fr. (HRCB); Corumbataí, 22S 13', 47W 37', 11/1993, K.D. Barreto et al. 1568, fl. (ESA); Cunha, 23S 4', 44W 57', 20/3/1996, C.B. Costa et al. 210 \& 212, fr. (SP); Iguape, 24S 42', 47W 33', 19/2/1996, C.B. Costa et al. 120, fl., fr. (SP); Iporanga, 24S 35', 48W 35', 21/5/1996, C.B. Costa et al. 237, fr. (SP, UEC), 260, fl., fr. (SP); Itapeva, 23S 58', 48W 52', 11/2/1995, P.H. Miyagi et al. 282, fl., fr. (ESA, SP, UEC); Itararé, 24S 6', 49W 19', 25/1/1996, V.C. Souza et al. 10501, fl. (ESA, SP, UEC); Joanópolis, 22S 55', 46W 16', 11/4/1995, J.Y. Tamashiro et al. 789, fl., fr. (ESA, HRCB, SP, SPF, UEC); Luís Antônio, 21S 33', 47W 42', 12/1991, M.R. Mecbi \& S. Mateus 83, fl. (SPFR); Pindamonhangaba, 22S 55', 45W 27', 31/3/1994, L. Rossi et al. 1468, fl., fr. (ESA, HRCB, SP, SPF, UEC); Salesópolis, 23S 31', 45W 50', 6/9/1994, R.T. Shirasuna et al. 40, fr. (SP); Santa Rita do Passa Quatro, 21S 42', 47W 28', 2/1997, M. Batalha 1587, fr. (SP); São Carlos, 22S 1', 47W 53', 13/5/1997, C.B. Costa et al. 265, fr. (SP); São Paulo, 23S 32', 46W 38', 26/10/1917, F.C. Hoehne s.n., est. (SP 779); Teodoro Sampaio, 22S 31', 52W 10', 18/5/1995, M. Kirizawa \& E.A. Lopes 3152, fr. (SP); Ubatuba, 23S 26', 45W 4', 2/2/1996, H.F. Leitão Filho et al. 34615, fl., fr. (ESA, SP, UEC).

Distribuição geográfica e ecologia - apresenta ampla distribuição nos Neotrópicos, ocorrendo desde o sul do México até a Argentina, exceto na região amazônica. No Brasil, é econtrada nos estados das regiões Sul e Sudeste, em Goiás, Mato Grosso e Mato Grosso do Sul. Habita as florestas ombrófilas densas, cerradões e subosque de Eucalyptus.

Esta espécie caracteriza-se pelo indumento velutino, folhas com 7-12 pares de nervuras secundárias, inflorescências globosas, pedunculadas, com numerosas flores pequenas, lobos do cálice ovais ou lineares, geralmente reflexos e bagas elipsóides ou obovóides, de coloração azul-brilhantes. Schumann (1889) considerou $C$. lanceolatum sinônimo de $C$. condalia Pers. Segundo este autor, C. condalia possui ampla variação morfológica, sendo uma erva glabra ou pubescente, com folhas ovais a oval-lanceoladas, raramente lanceoladas, 5-6 pares de nervuras secundárias, base cordada ou truncada, lobos do cálice lanceolados ou oblongos, mais ou menos pubescentes, raramente glabros e inflorescências globosas com uma ou muitas flores. Já $C$. lanceolatum é uma erva 
velutina, com folhas usualmente lanceoladas, 7-12 pares de nervuras secundárias, base arredondada ou assimétrica, lobos do cálice ovais ou lineares, velutinos e inflorescências globosas com muitas flores.

Utilizando-se a chave de espécies da Flora Brasiliensis, os materiais aqui considerados como $C$. lanceolatum, enquadram-se na descrição de $C$. canescens (Schumann 1889). Esta é caracterizada como uma erva tomentosa ou lanuginosa, vinácea ou alva, com folhas ovallanceoladas ou oblongas, raramente lanceoladas, com 8-10 ou 12-13 pares de nervuras secundárias, inflorescências globosas com muitas flores, lobos do cálice oval-oblongos ou obovais e densamente pilosos de ocorrência nos Estados da Bahia, Minas Gerais, Rio de Janeiro e Santa Catarina. Standley (1930b), ao estudar as Rubiaceae da Colômbia, restabeleceu $C$. lanceolatum e sinonimizou $C$. canescens, com o comentário de que os materiais normalmente identificados como C. canescens Ruiz \& Pav. enquadravam-se na descrição de Condalia lanceolata. Steyermark (1967) utilizou como características distintivas, não só o grande número de flores na inflorescência, mas também a forma oblanceolada, obovada ou largamente elíptica dos lobos do cálice, e o fato destes serem levemente reflexos. Este autor comentou ainda que esta característica permanecia constante para a espécie, a despeito da grande variabilidade encontrada na forma da lâmina, base e ápice das folhas e comprimentos do pecíolo e do pedúnculo da inflorescência. A presença de lobos do cálice reflexos nas flores é evidente na descrição e ilustração feitas por Steyermark (1974) num estudo para a Venezuela; o autor comentou ainda que estes poderiam, eventualmente, aparecer estendidos, ao invés de reflexos. Dwyer (1980), ao referir a espécie no Panamá, caracterizou os lobos do cálice como ovais ou oblongos, com 3(-6) mm de comprimento e estendidos.

No Estado de São Paulo, foram encontradas populações que apresentavam lobos do cálice reflexos ou estendidos, sendo a primeira a forma mais comum. A análise de todo o material disponível, mostrou ainda grande variação com relação ao indumento e coloração dos ramos e folhas, tamanho das folhas e número de flores nas inflorescências. Espécimes coletados principalmente em áreas de cerradão, apresentam normalmente ramos vináceos, lobos do cálice linear-lanceolados, estendidos e inflorescências laxas. Tal variação foi observada também em espécimes coletados neste mesmo ambiente, em outros Estados. Foi possível observar ainda que, nas populações que habitam locais ensolarados, os ramos e folhas apresentavam-se verdes e com indumento alvo, enquanto que naquelas de locais sombreados, os ramos, folhas e indumento eram vináceos. Como uma erva prostrada, o ápice dos ramos aparecem voltados para cima, expondo as flores; já os frutos permanecem sob as folhas, voltados para o solo; apesar disso, são facilmente visualizados devido à cor azul intensa.

C. lanceolatum assemelha-se a C. crassifolium Standl., de ocorrência no Rio de Janeiro. A análise da foto do holótipo desta última, evidenciou uma grande semelhança entre ambas, podendo tratar-se de sinônimos.

8. Coccocypselum lymansmithii Standl., Field Mus. Nat. Hist., Bot. Ser. 8(3): 165.1930.

Figuras - 3P-U, 4A

Material selecionado BRASIL: SÃO PAULO: Campos do Jordão, 22S 44', 45W 35', 20/12/1995, S.A. Nicolau \& J.R. Manna de Deus 991 \& 1006, fl. (SP), 13/6/1992, A. Sciamarelli et al. 26559, fl., fr. (UEC), 6/1950, M. Kuhlmann 3377, fl. (SP); Moji-Guaçu, 22S 22', 46W 56', 9/1960, G. Eiten \& L.T. Eiten 2338, fl., fr. (SP); Pindamonhangaba, 22S 55', 45W 27', 29/3/1994, L. Rossi et al. 1422, fl., fr. (ESA, HRCB, SP, SPF, UEC); São Paulo, 23S 32', 46W 38', 12/1932, A.C. Brade 12367, fr. (R, RB).

Distribuição geográfica e ecologia - ocorre do Rio de Janeiro ao sul do Brasil, e em São Paulo, preferencialmente nos campos montanos das Serras do Mar e da Mantiqueira.

C. lymansmithii foi descrita como uma erva de caule delgado, com tricomas patentes, estípulas diminutas, folhas com pecíolo curto, lâminas orbiculares ou ovalorbiculares, face adaxial enerva, abaxial vinácea, com tricomas esparsos e nervuras pouco proeminentes, flores solitárias, pedicelos iguais ou maiores que os pecíolos, brácteas lineares, obtusas, hipanto semigloboso e lobos do cálice lineares ou linear-oblongos, eretos (Standley 1930a). Com exceção de um material proveniente de Campos do Jordão, que apresenta inflorescências bifloras, todos os demais apresentaram flores solitárias. Uma análise mais ampla é necessária para confirmar se há realmente variação no número de flores nas populações. Assemelha-se a $C$. reitzii L.B.Sm. \& Downs, espécie de Santa Catarina (Smith \& Downs 1956), diferenciando-se por esta apresentar inflorescências com 3-4 flores. C. pumilio Standl., descrita para os campos arenosos do Paraná (Standley, 1931), assemelha-se também a esta espécie, por apresentar folhas pequenas e inflorescência uniflora, podendo tratar-se de um provável sinônimo de $C$. lymansmithii.

\section{Discussão}

As espécies de Coccocypselum estudadas compõem o estrato herbáceo principalmente das florestas ombrófilas densas, podendo ocorrer ainda nas bordas das matas. Existe grande variabilidade na forma e tamanho das folhas, e no número de nervuras secundárias, sendo que tais características foram importantes na delimitação das espécies estudadas.

As espécies são inteiramente herbáceas, sendo ervas repentes, prostradas e decumbentes. O hábito herbáceo e repente pode ser considerado para a totalidade das espécies do gênero, a despeito de algumas observações feitas nas etiquetas de alguns materiais, de que seriam ervas trepadeiras ou epífitas.

$\mathrm{Na}$ face adaxial da lâmina foliar, as nervuras primária e secundárias aparecem impressas na lâmina, deixando a superfície sulcada. Na face abaxial, elas são proeminentes. Estas características são particularmente evidentes em $C$. hasslerianum, que possui ainda a região de inserção dos 
tricomas bastante evidente (fig. 4C). Nas demais espécies este é um caráter mais discreto. C. cordifolium, $C$. campanuliflorum e $C$. lanceolatum apresentam as nervuras primária e secundárias da face abaxial totalmente revestidas de tricomas, o que as torna bastante distintas. As nervuras secundárias são de 3-11 e sempre opostas. A forma e dimensão do pecíolo e da lâmina foliar, além do indumento, são características importantes na distinção das espécies, apesar de estarem sujeitas a grande variabilidade, influenciada pelas modificações do ambiente. O padrão de venação das folhas é eucamptódromo, para todas as espécies estudadas, com as nervuras secundárias curvas, ascendentes, terminando em arcos imperfeitos (fig. 3Q).

O indumento das espécies estudadas é constituído de tricomas pluricelulares, simples, unisseriados ou incompletamente septados, com paredes celulares externas espessas e os septos mais delgados que estas. Já o indumento da face adaxial da corola compõe-se de tricomas unicelulares, moniliformes, com paredes delgadas. Estes tricomas formam uma faixa na porção mediana do tubo da corola e estão associados às estruturas reprodutivas e à forma heterostílica da flor (fig. 1E, F). O indumento é sempre uniforme, ocorrendo tricomas do mesmo tipo em todas as estruturas da planta, com variação apenas no tamanho. As espécies podem variar de totalmente glabras (C. condalia, C. krauseanum), glabrescentes ou seríceas (C. condalia, C. krauseanum), velutinas ( $C$. lanceolatum), ou hirsutas $(C$. campanuliflorum, C. cordifolium, C. condalia, $C$. erythrocephalum, $C$. hasslerianum).

Para muitas espécies de Coccocypselum, a densidade do indumento é um caráter distintivo. Porém, quando se analisa uma grande quantidade de material, de ampla distribuição e ocorrência em diferentes ambientes, é possível verificar que esta característica é bastante variável.

A presença de pedúnculo nas inflorescências tem sido uma das características mais empregadas na separação das espécies de Coccocypselum. Apesar de muitas vezes o comprimento do pedúnculo estar relacionado ao desenvolvimento da inflorescência, nas populações analisadas suas dimensões permaneciam mais ou menos constantes, sendo um importante caráter na separação das espécies estudadas.

As características florais são constantes nas espécies de Coccocypselum, ocorrendo poucas variações significativas, como no indumento e na forma e comprimento dos lobos do cálice. Nas populações observadas, estavam presentes normalmente as duas formas distílicas, sendo mais freqüente formas longistilas.

Todas as espécies estudadas possuem frutos carnosos com mesocarpo esponjoso e esbranquiçado, à exceção de C. campanuliflorum. A análise de populações com frutos mostrou ser este um importante caráter para auxiliar na identificação das espécies, caráter este pouco utilizado, provavelmente devido ao fato dos frutos carnosos serem danificados no processo de herborização. Destacam-se aqui as observações feitas para os frutos de $C$. campanuliflorum, que, ao contrário das demais espécies, iniciam seu desenvolvimento como carnosos, tornando-se secos quando maduros, sendo necessário o acompanhamento de populações e estudos anatômicos a fim de elucidar sua verdadeira natureza.

As espécies de Coccocypselum de São Paulo florescem e frutificam durante todo o ano, com exceção de $C$. erythrocephalum e $C$. hasslerianum. Os períodos de floração e frutificação são contínuos e muitas vezes é possível encontrar flores e frutos numa mesma população. $C$. erythrocephalum e $C$. hasslerianum apresentam flores preferencialmente no outono.

Sete espécies de Coccocypselum ocorrem nas florestas ombrófilas densas do litoral do Estado de São Paulo. $C$. campanuliflorum, $C$. condalia e $C$. lanceolatum são espécies de ampla distribuição, sendo também as mais frequientes nestas formações. $C$. lanceolatum e $C$. condalia possuem ampla distribuição no Estado e no Brasil, podendo ainda ser encontradas em áreas de vegetação secundária. Esta última aparece ainda em áreas de florestas ombrófilas mistas e campos montanos. C. lymansmithii apresenta distribuição restrita, ocorrendo em São Paulo apenas nos campos montanos do norte do Estado. Outra espécie de distribuição restrita é $C$. erytrocephalum, presente apenas nas florestas ombrófilas densas, também do norte do Estado. C. cordifolium, $C$. krauseanum e $C$. erytrocephalum ocorrem nas florestas ombrófilas densas, em locais bem úmidos, sendo suas populações menos freqüentes que as demais espécies. C. lanceolatum é a única espécie que ocorre nos cerradões do interior do Estado. Nenhuma das espécies de Coccocypselum estudadas foi registrada para as áreas de floresta estacional semidecidual e floresta ombrófila densa aluvial do interior do Estado, como também nas formações de dunas e manguezais do litoral.

\section{Agradecimentos}

As autoras agradecem ao Instituto de Botânica e ao Depto de Botânica do Instituto de Biociências da USP, pela utilização das instalações e infra-estutura cedidas durante a realização do presente trabalho; aos curadores dos herbários cujas siglas são citadas no texto, pelo empréstimo e permissão de consulta ao seu acervo; à CAPES e ao CNPq pelas bolsas concedidas; à Coordenação do Projeto Flora Fanerogâmica do Estado de São Paulo, pelo apoio; e à artista Emyko Naruto, pela cobertura a nanquim das ilustrações.

\section{Referências bibliográficas}

1. ANDERSSON, L. 1992. A provisional checklist of Neotropical Rubiaceae. Scripta botanica belgica 1: 1-199.

2. CHAMISSO, A. \& SCHLECHTENDAL, D. 1829. Rubiaceae. Linnaea 4: 12-202.

3. DUBS, B. 1998. Prodromus florae matogrossensis Rubiaceae. The Botany of Mato Grosso 3(1): 1-254. 
4. DWYER, J.D. 1980. Flora of Panamá. 179. Rubiaceae. Ann. Missouri Bot. Gard. 67(1): 1-256.

5. GOMES, M. 1996. Rubiaceae. In Reserva Ecológica de Macaé de Cima, Nova Friburgo, RJ. Aspectos Florísticos das Espécies Vasculares (M.P. Morim de Lima \& R.R. Guedes-Bruni, eds.). Rio de Janeiro: Jardim Botânico do Rio de Janeiro, v.2, p.345-426.

6. JUNG-MENDAÇOLLI, S.L. 1994. Flora Fanerogâmica da Reserva do Parque Estadual das Fontes do Ipiranga (São Paulo, Brasil). 155 - Rubiaceae. Hoehnea 21(1/2): 97-129.

7. JUNG-MENDAÇOLLI, S.L. 1999. Rubiaceae. In Flora Fanerogâmica da Ilha do Cardoso (M.M.R.F. Melo, F. Barros, S.A.C. Chiea, M. Kirizawa, S.L. JungMendaçolli \& M.G.L. Wanderley, eds.). São Paulo: Instituto de Botânica, v.6, p.45-136.

8. KRAUSE, K. \& HOEHNE, F.C. 1922. Contribuições ao conhecimento das Rubiáceas do Brasil Meridional. Mem. Inst. Butantan (São Paulo) 1(3): 1-32.

9. LAWRENCE, T.J. \& GREEN, P.S. 1993. The anatomy of dehiscent berry. Kew Bull. 48(1): 53-57.

10. LOEFGREN, A. 1896. Ensaio para uma distribuição dos vegetais nos diversos grupos florísticos no Estado de São Paulo: Índice das plantas do herbário da Commissão, cultivadas no jardim da Commissão. Boletim da Comissão Geográphica e Geológica da Província de São Paulo, n. 11.

11. MORI, S.A.; SILVA, L.A.M.; LISBOA, G. \& CORADIN, L. 1989. Manual de manejo do herbário fanerogâmico. Ilhéus: CEPLAC.

12. NIMER, E. 1979. Climatologia do Brasil. Fundação Instituto Brasileiro de Geografia e Estatística.

13. RADFORD, A.E.; DICKISON, W.C.; MASSEY, J.R. \& BELL, C.R. 1974. Vascular Plant Systematics. Harper \& Row Publ., New York.

14. SCHUMANN, K. 1889. Rubiaceae (Tribo Mussaendae). In Flora Brasiliensis (C.P.F. Martius, A.G. Eichler \& I. Urban, eds.). F. Fleischer, Lipsiae, v.6, pars 6, p.279-318.

15. SMITH, L.B. \& DOWNS, R.J. 1956. Resumo preliminar das Rubiaceae de Santa Catarina. Sellowia 7: 13-92.

16. STANDLEY, P.C. 1930a. Rubiaceae. In Studies of American Plants VI (B.E. Dahlgren, ed.). Field Mus. Nat. Hist., Bot. Ser. 8(3): 151-236.

17. STANDLEY, P.C. 1930b. The Rubiaceae of Colombia. Field Mus. Nat. Hist., Bot. Ser. 7(1): 3-175.

18. STANDLEY, P.C. 1931. The Rubiaceae of Bolivia. Field Mus. Nat. Hist., Bot. Ser. 7(3): 255-339.

19. STANDLEY, P.C. 1936. Rubiaceae. In Studies of American Plants VI (B.E. Dahlgren, ed.). Field Mus. Nat. Hist., Bot. Ser. 11(5): 176-274.

20. STANDLEY, P.C. \& WILLIAMS, L.O. 1975. Flora of Guatemala. 11- Rubiaceae. Fieldiana: botany 24(1/3): 1-274.

21. STEYERMARK, J.A. 1967. Rubiaceae. In Botany of the Guayana Highlands, Part VII (B. Maguire \& J.J. Wurdack, eds.). Mem. New York Bot. Gard. 17(1): $230-436$.
22. STEYERMARK, J.A. 1974. Rubiaceae. In Flora da Venezuela (T. Lasser, ed.), v.9, pars 1, p.478-494.

23. USTERI, A. 1911. Flora der Umgebung der Stat São Paulo. Jena: Verlag.

24. VELOSO, H.P.; RANGEL FILHO, A.L.R. \& LIMA, J.C.A. 1991. Classificação da Vegetação Brasileira, adaptada a um Sistema Universal. Fundação Instituto Brasileiro de Geografia e Estatística, Rio de Janeiro.

Título: Sinopse do Gênero Coccocypselum P. Browne (Rubiaceae) no Estado de São Paulo, Brasil

Autor: Cristina Bestetti Costa e Maria Candida Henrique Mamede

Biota Neotropica, Volume 2, número 1, 2002 http://www.biotaneotropica.org.br/v2n1/pt/abstract?articl e+BN01502012002

Recebido 19 de fevereiro de 2002

Modificado em 03 de maio de 2002

Aceito em 21 de maio de 2002

ISSN 1676-0603 


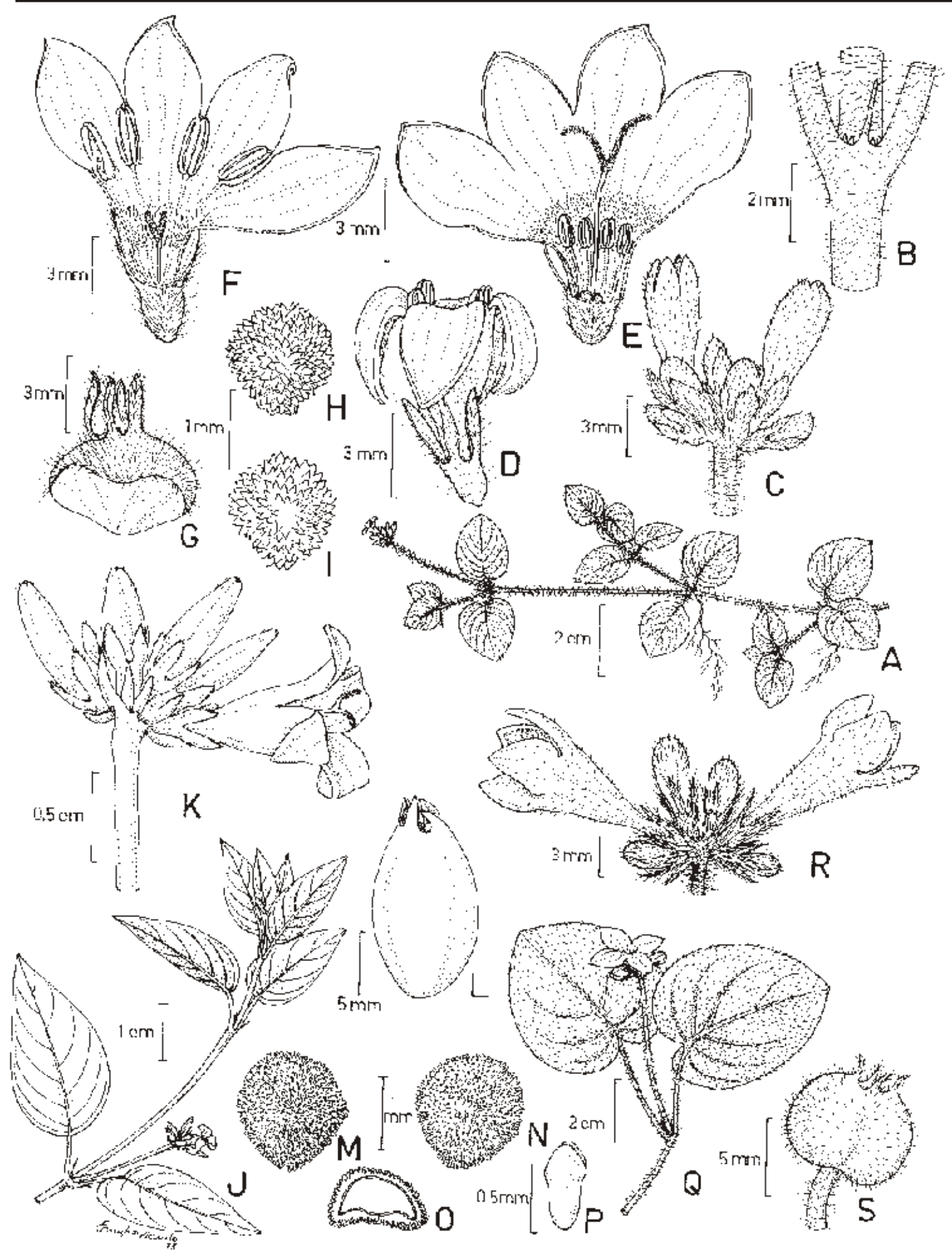

Figura 1. A-I. Coccocypselum campanuliflorum: A. Hábito. B. Estípula. C. Inflorescência. D, F. Flor brevistila. E. Flor longistila. G. Fruto. H-I: Semente, vista dorsal (H) e ventral (I). J-P. C. condalia: J. Ramo florido. K. Inflorescência. L. Fruto. M-O: Semente, vista dorsal (M), ventral (N) e em corte transversal (O). P. Embrião. Q-S. C. cordifolium: Q. Ramo florido. R. Inflorescência. S. Fruto. (A, D-F, Oliveira s.n., SP 310949; B, Costa 62; C, Anunciação 166; G-I, Kiyama 120; J, Costa 205; K, Garcia 788; L, Costa 209; M-P, Macias 96126; Q, Leitão Filho 34591; R, Mello-Silva 1001; S, Costa 216). 


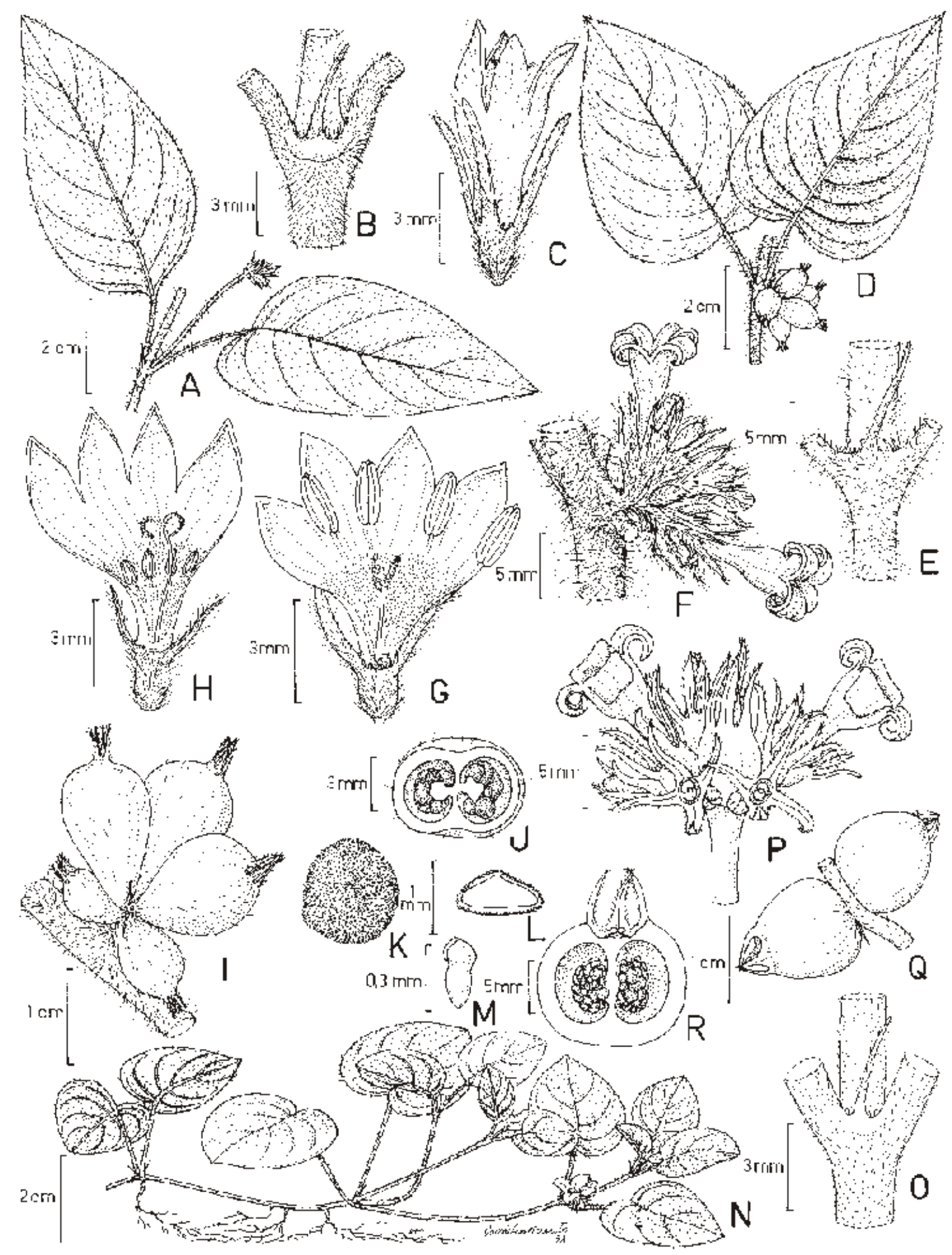

Figura 2. A-C. Coccocypselum erythrocephalum: A. Ramo florido. B. Estípula. C. Flor longistila. D-M. C. hasslerianum: D. Ramo frutífero. E. Estípula. F. Inflorescência. G. Flor brevistila. H. Flor longistila. I. Frutos. J. Fruto, corte transversal. K-L. Semente, vista dorsal (K) e em corte transversal (L). M. Embrião. N-R. C. krauseanum: N. Hábito. O. Estípula. P. Inflorescência. Q. Infrutescência. R. Fruto, corte longitudinal. (A-C, Costa 210; D, I-M, Costa 234; E-F, Costa 225; G, Furlan 1282; H, Jung-Mendaçolli 500; N, Mello-Silva 907; O, Sugiyama 1406; P, Nicolau 1003; Q, Costa 239; R, Costa 211). 


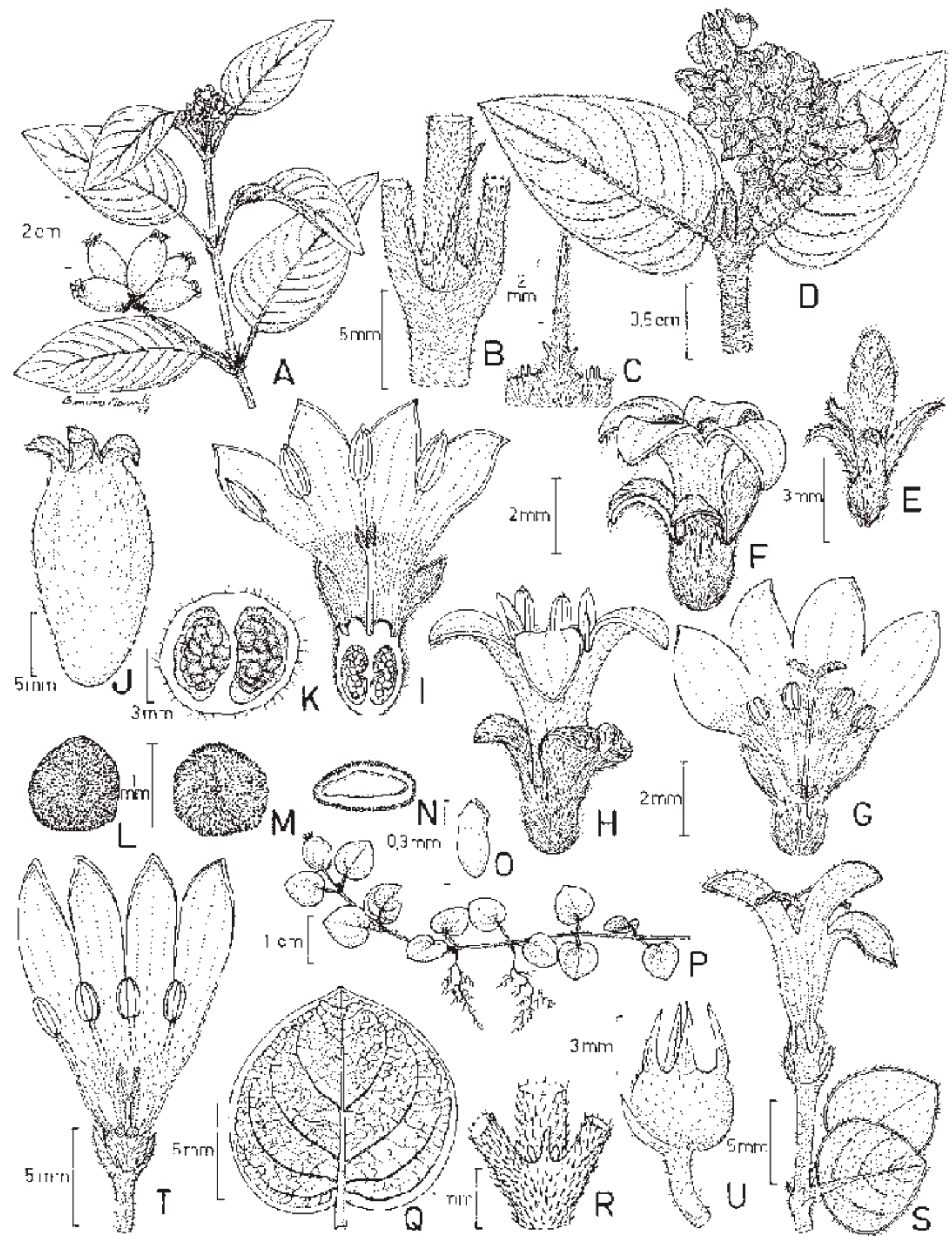

Figura 3. A-O. Coccocypselum lanceolatum: A. Ramo com flores e frutos. B. Estípula. C. Estípula, face interna. D. Inflorescência. E. Botão. F-G. Flor longistila. H-I. Flor brevistila. J. Fruto. K. Fruto, corte trasversal. L-N. Semente, vista dorsal (L), ventral (M) e em corte transversal (N). O. Embrião. P-U. C. lymansmithii: P. Hábito. Q. Folha diafanizada. R. Estípula. S. Inflorescência. T. Flor brevistila. U. Fruto. (A, Shirasuna 40; B-C, Rossi 1468; D, Costa 260; E, Souza 10501; F-G, Costa 120; H-I, Miyagi 282; J-O, Costa 237; P-Q, T-U, Rossi 1422; R-S, Nicolau 991). 


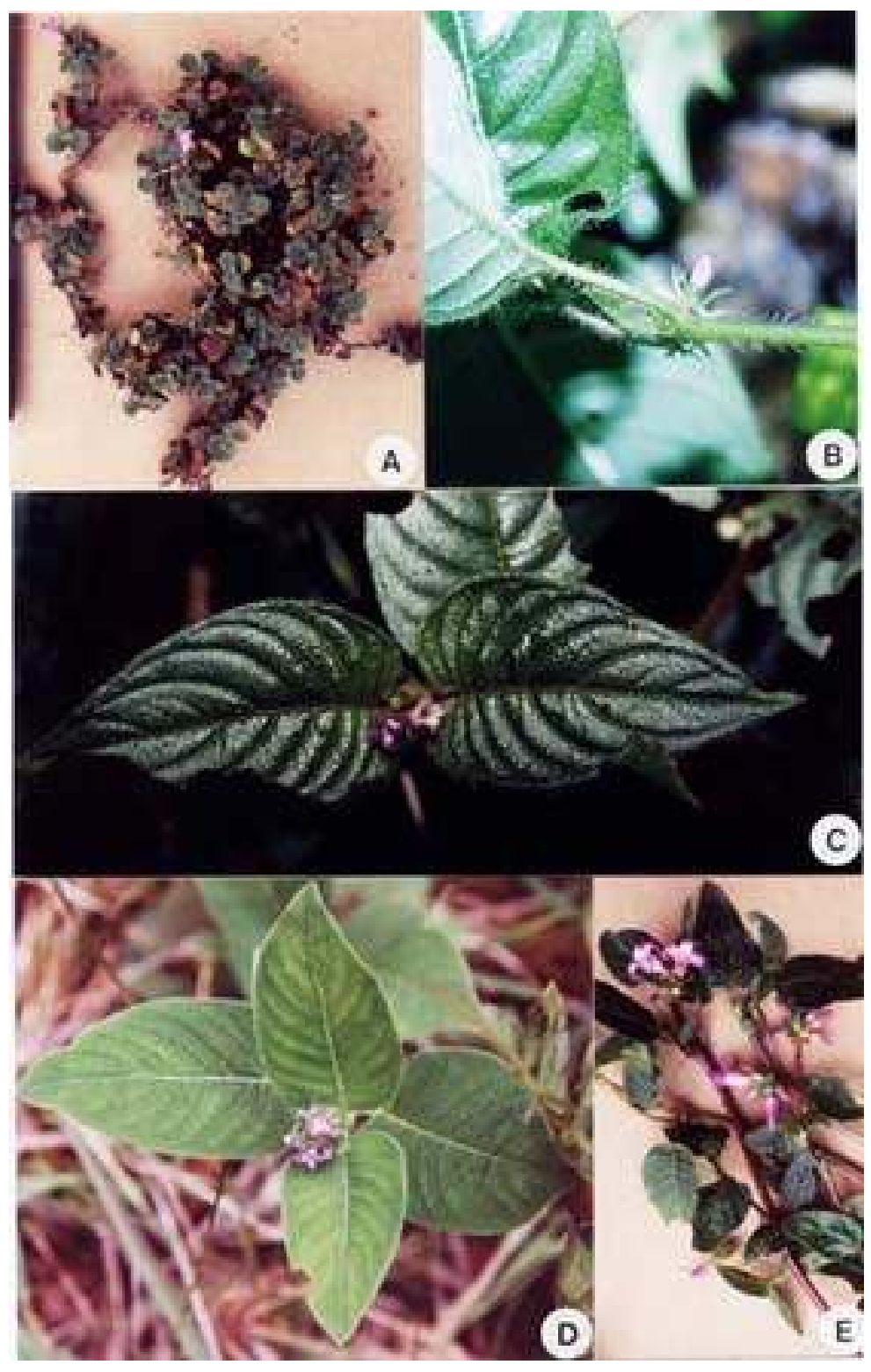

Figura 4. A-E. Aspecto das inflorescências de algumas espécies de Coccocypselum. A. C. lymansmithii: hábito. B-C. C. hasslerianum: ramo com inflorescência. D. C. lanceolatum: ramo com inflorescência. E. C. condalia: inflorescências. A, Nicolau 1006.; B-C, Costa 225; D, Costa 120; E, Nicolau 999. 


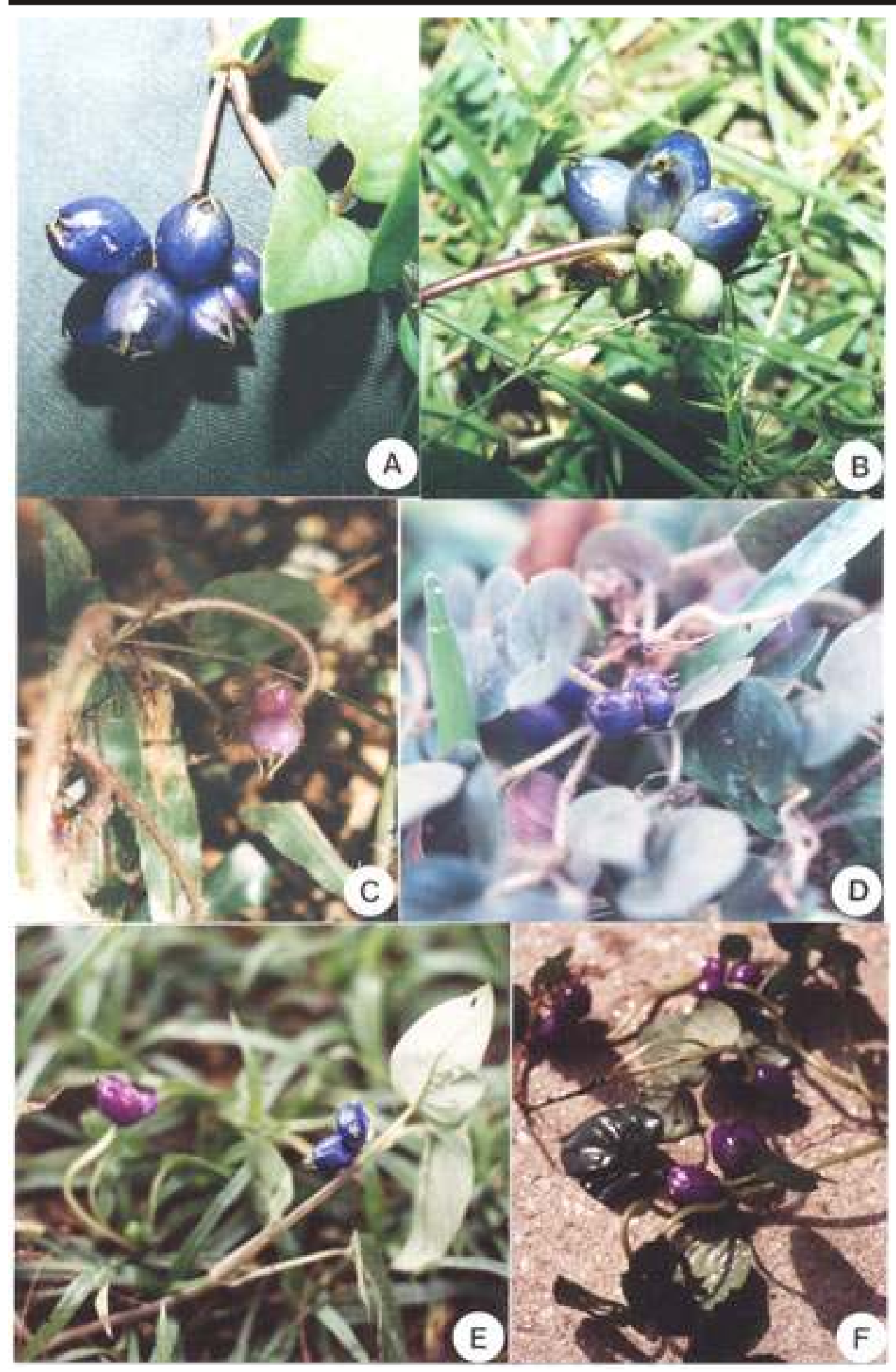

Figura 5. Variação dos frutos de Coccocypselum. A-B. C. condalia: A. Frutos maduros. B. Frutos imaturos. C-D. C. cordifolium: C. Frutos imaturos. D. Frutos maduros. E-F. C. krauseanum: E. Frutos maduros e imaturos. F. Frutos imaturos. A-B, Costa 207; C, Sugiyama 1411; D, Costa 219; E-F, Wanderley 2245. 